\title{
Shape memory polymer networks based on methacrylated fatty acids
}

\author{
Guillermina Capiel, Norma E. Marcovich , Mirna A. Mosiewicki * \\ Instituto de Investigaciones en Ciencia y Tecnología de Materiales (INTEMA), Facultad de Ingeniería, Universidad Nacional de Mar del Plata - CONICET, Mar del Plata, \\ Argentina
}

\section{A R T ICLE INFO}

\section{Keywords:}

Bio-based polymers

Fatty acid based precursors

Shape memory behavior

\begin{abstract}
A B S T R A C T
In this study, bio-based materials were prepared from fatty acid precursors and variable amounts of styrene or divinylbenzene by free-radical polymerization. The obtained materials were highly translucent and resulted insoluble in common organic and aqueous solvents. They exhibit a complex microstructure due to the formation of highly cross-linked arrangements (micro/nanogels) closed packed into clusters. The bio-polymers prepared with divinylbenzene (a tetra-functional monomer), due to their excessive cross-linkage, resulted in brittle samples whose mechanical response could not be obtained. On the other hand, bio-based polymers obtained from styrene (a bi-functional monomer) resulted in materials with a moderate cross-linking density, a sharp glass-rubber transition and acceptable mechanical properties, leading to polymers with interesting shape memory response (switching temperature, fixity and recovery ratios) that could be tailored by changing the composition. In these materials it was corroborated that higher (but not excessive) cross-linking density led to a greater shape recovery, since cross-links are the responsible for memorizing the original shape of the material.
\end{abstract}

\section{Introduction}

The development of novel bio-based materials with functional properties, like shape memory, has a great scientific and technological interest. First, the worldwide increasing concerns about sustainability and environmental issues demand to find alternatives for reducing or replacing the consumption of petroleum-derived raw materials. On the other hand, during the last years the interest in new smart materials with tailored responsive properties has grown due to the important role that these materials play in many applications because of their potential use in different disciplines (optics, electronics, aerospace, biomaterials, etc. [1-4]). In this context, the research on shape memory polymers (SMPs), which are a class of smart materials that are capable of fixing a transient shape and recovering their original dimensions by the application of an external stimulus [5], obtained from bio-based resources have received great attention during the last years [4,6-8]. The most extensively investigated kinds of SMPs are those thermally induced, where the recovery takes place when a certain transition temperature is exceeded. The switching temperatures are often the glass transition temperature in thermoset polymers or the melting temperature of soft segments in thermoplastic ones [5].

Vegetable oils and their derived fatty acids are the most common renewable raw materials selected to prepare novel bio-based polymers due to their high availability, high chemical versatility and low cost [9-11]. They are then, excellent candidates to be used in formulations of materials with interesting potential technological applications [9,10,12-17]. Accordingly, many efforts have been done to obtain thermoset polymers from oleochemical raw materials. Few of those works have focused in polymers with functional properties, reporting, for example, shape memory properties. Most of them were prepared by combining different proportions of a

\footnotetext{
* Corresponding author.

Email address: mirna@fi.mdp.edu.ar (M.A. Mosiewicki)
} 
vegetable oil (as modified soybean oil or tung oil), with styrene (ST) and/or divinylbenzene (DVB) $[8,18,19]$ while others were prepared from epoxidized vegetable oils (epoxidized soybean oil or epoxidized linseed oil) and a curing agents such as dicarboxylic acids and anhydrides [20,21]. Examples of the first group are the work of Meiorin et al. [8] that reports the mechanical, damping and shape memory behavior of copolymers obtained by cationic copolymerization of tung oil with styrene at different stoichiometric ratios and the work of Li and Larock [18] that deals with the synthesis and characterization of bio-polymers obtained by cationic copolymerization of regular soybean oil, low saturation soybean oil (LoSatSoy oil), and/or conjugated LoSatSoy oil with styrene and divinylbenzene, norbornadiene, or dicyclopentadiene. Regarding the second group, Wang et al. [20] cured epoxy polymers (EPs) derived from soybean oil with varied chemical compounds containing anhydride groups to yield soybean-oil-derived epoxy polymers ranging from soft elastomers to tough thermosets, whose properties were adjusted by using different EPs and/or by controlling feed ratios of EPs to anhydrides; Tsujimoto et al. [21] developed a polymer by curing epoxidized linseed oil with 4-methylhexahydrophthalic anhydride that showed excellent shape memory-recovery behavior. Likewise, sebacic acid was directly used to synthesize functional bio-polyesters by reacting it with 1,3-propanediol and itaconic acid [22]. The resulting polyesters exhibited excellent shape recovery properties (near $100 \%$, and are independent of thermo-mechanical cycles) with tunable switching temperature ranging from 12 to $54{ }^{\circ} \mathrm{C}$, the typical temperature range for biomedical applications in the human body. Goerz and Ritter [23] obtained fully biobased unsaturated from isosorbide, itaconic acid and succinic acid that, after cross-linking with dimethyl itaconate, exhibited a one-way shape memory effect upon heating after deformation at the glass transition temperature. More recently, bio-based cross-linked polyurethanes with both, the macrodiol and the diisocyanate derived from renewable sources, were synthesized and characterized as shape-memory polymers by Calvo-Correas et al. [24]. They reported that shape-memory response was influenced by cross-linking density: a higher crosslink density leading to a greater shape recovery.

In a previous work, we reported the synthesis of methacrylated fatty acid based precursors that were copolymerized in cationic and free radical polymerizations with styrene. The resulting materials presented glass transition temperatures (Tgs) higher than room temperature and promising shape memory behavior [25]. In this work, these fatty acid based monomers synthesized from lauric and oleic acids with glycidyl methacrylate were free radically copolymerized with styrene or divinylbenzene, leading to highly translucent materials in all cases. Moreover, some of the copolymers showed also good shape memory properties, relatively high deformability above $\mathrm{Tg}(50 \%)$ and switch temperatures above room temperature, as is presented below.

\section{Materials}

Oleic acid (OA), lauric acid (LA) and glycidyl methacrylate (GMA), used in the synthesis of the methacrylated fatty acid precursors, were supplied by Sigma Aldrich; the catalyst, 2-methylimidazole, was supplied by Fluka. Reagents were used as received.

The polymeric materials were obtained using the synthesized precursors and styrene (ST) supplied by Kubo (Argentina) or divinylbenzene (DVB) supplied by Sigma Aldrich. Benzoyl peroxide (BPO), from Sigma-Aldrich, was used as the initiator of the free-radical polymerizations.

\section{Methods and techniques}

\subsection{Synthesis of fatty acid based precursors}

The addition of the fatty acid (OA or LA) to the glycidyl methacrylate (GMA) was performed by mixing the selected fatty acid with GMA in a molar ratio of $1: 1.1$ with $2 \mathrm{wt} \%$ of catalyst (2-methylimidazole) in a stirred glass vessel at $70{ }^{\circ} \mathrm{C}$ during $5 \mathrm{~h}$ [25]. A thermostatic water bath was used to control the temperature.

The chemical structures of the methacrylated precursors obtained are shown in Fig. 1 [25]. Hereafter, they are designated as methacrylated oleic acid (MOA) and methacrylated lauric acid (MLA).

\section{Methacrylated oleic acid monomer (MOA)}<smiles>C=C(C)C(=O)OCC(O)COC(=O)CCCCCCC/C=C/CCCCCCCC</smiles>

\section{Methacrylated lauric acid monomer (MLA)}<smiles>C=C(C)C(=O)OCC(O)COC(=O)CCCCCCCCCCC</smiles>

\section{Styrene (ST)}

\section{Divinylbenzene (DVB)}

Fig. 1. Chemical structure of the obtained methacrylated fatty acid precursors. 


\subsection{Preparation of polymeric materials}

Mixtures of $50 w t \%$ and $70 w t \%$ of styrene and $30 w t \%$ or $50 w t \%$ of divinylbenzene with the corresponding fatty acid monomer (MLA or MOA) were used to prepare materials by means of radical polymerization (using $1 \mathrm{wt} \% \mathrm{BPO}$ as initiator). The reactive mixtures were manually homogenized and then poured into a glass mold formed by plates of $13 \mathrm{~mm} \times 18 \mathrm{~mm}$ separated by a rubber cord $2 \mathrm{~mm}$ thick and kept closed with metal clamps. The curing cycle included two hours at $50^{\circ} \mathrm{C}, 1.5 \mathrm{~h}$ at $90^{\circ} \mathrm{C}$ and $1.5 \mathrm{~h}$ at $150^{\circ} \mathrm{C}$. The heating ramp between each stage was at $5^{\circ} \mathrm{C} / \mathrm{min}$. Finally, sheets of $2 \mathrm{~mm}$ thickness were successfully obtained. The composition of prepared materials and the nomenclature used to identify them are summarized in Table 1.

\subsection{Color properties and opacity}

The color and the opacity of the materials were measured with a LOViBond Colorimeter RT500 (Neu-Isenberg, Germany) with an $8 \mathrm{~mm}$ diameter measuring area. A white standard color plate for the instrument calibration was used as a background for the color measurements. Color results were expressed according the coordinates of the color space CIELab [26](lightness ' $L$ ', red-green ' $a$ ' and yellow-blue ' $b$ '). The total color difference $(\Delta E)$ with respect to the white standard color plate and whiteness index $(W I)$, were determined by Eqs. (1) and (2) [27]:

$\Delta \mathrm{E}=\sqrt{(\Delta \mathrm{a})^{2}+(\Delta \mathrm{b})^{2}+(\Delta \mathrm{L})^{2}}$

$W I=100-\sqrt{(100-\mathrm{L})^{2}+\mathrm{a}^{2}+\mathrm{b}^{2}}$

where $\Delta L ; \Delta a$ and $\Delta b$ are the differentials between the color parameter of the samples and that of the white standard plate $(L=92.3$; $a=1.4 ; b=-0.9)$ used during measurements.

The opacity of the samples was determined according to the Hunter lab method, as the relationship between the opacity of each sample on a black standard $(Y b)$ and the opacity of each sample on a white standard (Yw) [28]. The opacity percentage ( $\left.O p=\frac{Y b}{Y w} * 100\right)$ was automatically calculated by the instrument. Color and opacity measurements were taken in triplicate for each sample.

\subsection{Solvent solubility}

The solubility of the prepared materials was tested by immersing the samples indifferent solvents (i.e. hexane, toluene, tetrahydrofuran, chloroform, ethyl acetate, dimethylformamide, acetone and water) at room temperature and at $60^{\circ} \mathrm{C}$ for 7 days.

\subsection{Scanning electron microscopy (SEM)}

Small specimens of each material were cut after being immersed in liquid air (fragile fracture) and their fractured surface (transversal area) were analyzed with a JEOL JSM-6460 LV scanning electron microscope. The pieces were coated with a thin layer of gold before they were observed under the microscope.

\subsection{Dynamic mechanical analysis (DMA)}

The dynamic mechanical properties of the materials were measured with an Anton Paar Physica MCR rheometer. Torsion geometry was used with rectangular specimens of $10 \mathrm{~mm} \times 40 \mathrm{~mm}$ and $2 \mathrm{~mm}$ in thickness. Measurements were performed as temperature sweeps in the range -20 to $150^{\circ} \mathrm{C}$ at a heating rate of $5^{\circ} \mathrm{C} / \mathrm{min}$.

Table 1

Compositions and nomenclature of prepared polymeric materials.

\begin{tabular}{ll}
\hline Name & Material composition \\
\hline 50-MOA/50-ST & MOA $50 w \mathrm{t} \%$-styrene $50 \mathrm{wt} \%$ \\
$50-\mathrm{MLA} / 50-\mathrm{ST}$ & MLA $50 \mathrm{wt} \%$-styrene $50 \mathrm{wt} \%$ \\
$30-\mathrm{MOA} / 70-\mathrm{ST}$ & MOA $30 \mathrm{wt} \%$-styrene $70 \mathrm{wt} \%$ \\
$30-\mathrm{MLA} / 70-\mathrm{ST}$ & MLA $30 \mathrm{wt} \%$-styrene $70 \mathrm{wt} \%$ \\
$70-\mathrm{MOA} / 30-\mathrm{DVB}$ & MOA70 wt $\%$-divinylbenzene $30 \mathrm{wt} \%$ \\
$70-\mathrm{MOA} / 30-\mathrm{DVB}$ & MLA $70 \mathrm{wt} \%$-divinylbenzene $30 \mathrm{wt} \%$ \\
$50-\mathrm{MOA} / 50-\mathrm{DVB}$ & MOA $50 \mathrm{wt} \%$-divinylbenzene $50 \mathrm{wt} \%$ \\
$50-\mathrm{MLA} / 50-\mathrm{DVB}$ & MLA50 wt $\%$-divinylbenzene $50 \mathrm{wt} \%$ \\
\hline
\end{tabular}


The applied frequency was $1 \mathrm{~Hz}$, and the deformation was kept at $0.1 \%$ to ensure working in the linear viscoelastic range. The glass transition temperature $(\mathrm{Tg})$ values were arbitrarily taken as the temperature at which a maximum in the tan $\delta$ curve was observed.

From the DMA results, the cross-linked density $(\nu)$ can be determined, according to Eq. (3), which is based on the rubber elasticity theory $[29,30]$ :

$\mathrm{G}^{\prime}=3 v R T$

where $G^{\prime}$ is the storage modulus of the cross-linked polymer in the rubbery plateau region, $R$ is the universal gas constant (8.314 $\mathrm{J} /$ $\mathrm{mol} \cdot \mathrm{K}$ ) and $\mathrm{T}$ is the absolute temperature $(\mathrm{K}), \mathrm{Tg}+40^{\circ} \mathrm{C}$.

\subsection{Tensile tests}

Tensile tests were performed at $20^{\circ} \mathrm{C}$ on micro-tensile specimens of $5 \mathrm{~mm} \times 35 \mathrm{~mm} \times 2 \mathrm{~mm}$ cut from the molded materials by means of a universal testing machine (Instron 8501). The crosshead speed was $5 \mathrm{~mm} / \mathrm{min}$. Young's modulus and yield strength were determined from the average values of at least four replicates for each sample.

\subsection{Thermal cyclic tests}

Thermal cyclic tests were performed on micro-tensile specimens of $5 \mathrm{~mm} \times 50 \mathrm{~mm} \times 2 \mathrm{~mm}$ using an universal testing machine equipped with a heating chamber (Instron 8501). Samples were first conditioned at the chosen temperature (Ts), in general selected above sample glass transition temperature $(\mathrm{Tg})$ for $5 \mathrm{~min}$ and subsequently elongated to50\%of their original length (arbitrarily set as the maximum strain of each cycle, $\varepsilon_{\mathrm{m}}$ ) at a speed of $5 \mathrm{~mm} / \mathrm{min}$. Then, the samples were cooled below their Tgs by applying a thermal fault locator spray and unloaded. In this point, the residual strain $\left(\varepsilon_{u}\right)$ was recorded. After that, the samples underwent the recovery process by heating for $15 \mathrm{~min}$ at $T s$ and the residual strain $\left(\varepsilon_{p}\right)$ was registered. The force generated for the specimen during heating under constrain was also registered and reported as "Actuation Force", $A_{f}[31]$. The fixity $\left(R_{f}\right)$ and recovery $\left(R_{r}\right)$ ratios were determined as indicated in the following equations [5]:

$R_{f}=\frac{\varepsilon_{u}}{\varepsilon_{m}} \times 100 \%$

$R_{f}=\frac{\varepsilon_{m}-\varepsilon_{p}}{\varepsilon_{m}} \times 100 \%$

Moreover, to assess the dependence of the shape recovery with the number of cycles, this parameter was also evaluated as:

$\mathrm{R}_{\mathrm{r}(\mathrm{N})}=\frac{\varepsilon_{m}-\varepsilon_{p}(\mathrm{~N})}{\varepsilon_{m}-\varepsilon_{p}(\mathrm{~N}-1)} \times 100 \%$

where $\varepsilon_{p}(N)$ represents the residual strain after heating at $45^{\circ} \mathrm{C}$ in the $N^{\text {th }}$ cycle, and the amount $\varepsilon_{m}-\varepsilon_{p}(N-1)$ represents the maximum deformation that suffered the sample during the previous cycle.

\section{Results and discussion}

The materials obtained after the radical polymerization of the synthesized MOA and MLA monomers with different weight quantities of styrene ( $50 \mathrm{wt} \%$ and $70 \mathrm{wt} \%$ ) and divinylbenzene (30 wt $\%$ and $50 \mathrm{wt} \%$ ) were macroscopically homogeneous and highly translucent.

Quantitative results that confirm the naked visual observation are the opacity and color properties, shown in Table 2 . The opacity is related to the light that passes through a material: the higher the opacity, the lower the amount of light that can pass through

Table 2

Opacity and color parameters of the obtained materials.

\begin{tabular}{|c|c|c|c|c|c|c|}
\hline Sample & $L$ & $a$ & $b$ & $\Delta E$ & $W I$ & $O p(\%)$ \\
\hline White standard & 92.8 & 1.38 & -0.86 & & & \\
\hline 50-MOA/50-ST & $83.3 \pm 0.3$ & $-7.3 \pm 0.0$ & $37.4 \pm 1.1$ & $40.3 \pm 1.0$ & $58.4 \pm 1.0$ & $4.5 \pm 0.1$ \\
\hline 50-MLA/50-ST & $84.8 \pm 0.3$ & $-4.0 \pm 0.0$ & $17.8 \pm 0.4$ & $20.8 \pm 0.4$ & $76.3 \pm 0.4$ & $5.5 \pm 0.2$ \\
\hline 30-MOA/70-ST & $82.2 \pm 0.4$ & $-4.6 \pm 0.1$ & $30.8 \pm 0.6$ & $33.7 \pm 0.7$ & $64.2 \pm 0.7$ & $6.5 \pm 0.4$ \\
\hline 30-MLA/70-ST & $83.1 \pm 0.2$ & $-3.8 \pm 0.1$ & $22.7 \pm 0.3$ & $25.8 \pm 0.4$ & $71.5 \pm 0.4$ & $8.7 \pm 0.4$ \\
\hline 70-MOA/30-DVB & $83.3 \pm 0.3$ & $-7.3 \pm 0.0$ & $37.4 \pm 0.1$ & $40.3 \pm 1.0$ & $58.4 \pm 1.0$ & $3.0 \pm 0.3$ \\
\hline 70-MLA/30-DVB & $84.3 \pm 0.4$ & $-4.9 \pm 0.1$ & $25.4 \pm 0.2$ & $28.2 \pm 0.3$ & $69.7 \pm 0.3$ & $4.7 \pm 0.1$ \\
\hline 50-MOA/50-DVB & $82.7 \pm 0.1$ & $-6.4 \pm 0.2$ & $34.1 \pm 1.2$ & $37.1 \pm 1.1$ & $61.2 \pm 1.1$ & $8.4 \pm 0.4$ \\
\hline 50-MLA/50-DVB & $84.5 \pm 0.0$ & $-4.7 \pm 0.0$ & $22.2 \pm 0.1$ & $25.1 \pm 0.0$ & $72.5 \pm 0.0$ & $5.2 \pm 0.6$ \\
\hline
\end{tabular}


the sample [32,33]. In this case, mean opacity values for all polymers are less than $9 \%$, indicating that they are practically transparent. Even so, there are significant differences among samples that can be related with their chemical composition: opacity values increase as the amount of styrene or divinylbenzene increases and samples obtained from MOA-ST are slightly more transparent that their counterparts prepared from MLA. In a multi-phase material the light transmittance decreases (as compared with the corresponding to a homogeneous material) due to light dispersion or reflection at the phase interface [34]. In this case, the obtained bio-based polymers develop a special morphology that involves the formation of micro/nano gel regions, with increasing number as the cross-linker content increases, that act as dispersion/reflecting zones, resulting in increased opacity values. This will be further explained in the next sections.

Accordingly with the previous observations, the differences in lightness $(L)$ among the samples are small (ST containing samples) or not even significant (DVB based samples). Taking into account that the chromaticity components of the color space CIELab were obtained on a standard white plate, a decrease of $L$ value indicates a decrease of transparency, confirming that increasing amounts of styrene lead to less transparent or more opaque samples, as indicated above. Regarding fatty acid influence, the use of MLA contributes to strengthen the color of the polymers. Red-green (a) coordinate become less negative with the increase in STor DVB and with the use of the monomer MLA, indicating that the materials becomes lightly more red (or less green). On the other hand, yellow-blue $(b)$ coordinate and total color differences $(\Delta E)$ decrease, in general, with the increase in ST or DVB content; additionally, all values are lower for the materials derived from MLA in comparison with their counterparts made from MOA. The decrease in $b$ denotes a trend to more bluecolor. WI values are higher for MLA derived samples and the increase of ST or DVB content mostly leads to slightly higher values, indicating a certain loss of color or gain of white of the samples.

The solubility of the polymers was tested by immerging samples of each material in different solvents at room temperature and at $60^{\circ} \mathrm{C}$ for 15 days. All the materials resulted insoluble indicating that the obtained polymers are cross-linked, which was further confirmed by dynamic mechanical analysis, as will be explained later.

The main chemical structures of MLA and MOA, shown in Fig. 1, reveal that the precursors have one terminal carbon-carbon unsaturation highly reactive in free radical polymerization reactions, while the unsaturation between carbon 9 and 10 in the oleic acid that remains in the MOA precursor has very low reactivity in radical polymerizations [35]. Consequently, cross-linked networks are certainly expected for the materials prepared from MLA or MOA reacted with DVB, but this is not so obvious for those reacted with styrene. However, taking into account the results of the solubility tests, it is clear that all the obtained materials behave as thermoset networks [25]. Thus, to explain the features of the obtained structures it is needed to consider different facts that can contribute to the complex networks generated. On the one hand, competitive reactions could take place during the synthesis of the precursors or either during the polymerization with the synthetic monomers. In this sense, side reactions could lead to species of higher molecular weight than that of the products presented in Fig. 1 and some of them could derivate in macromolecules containing more than one co-polymerizable carbon-carbon double bond. Specifically, it could happen that once the monomer starts to be formed by the chemical reaction between the fatty acid and the glycidyl metacrylate, secondary reaction between the OH group (alcohol group) present in its structure (see Fig. 1) and an epoxy group (of the still unreacted GMA) occurs during the monomer synthesis, as was avowed by Shechter and Wynstra (1956) [36]. These researchers studied different possible routes for the reactions of a glycidyl ether with alcohols, phenols, carboxylic acids, and acid anhydrides [36], demonstrating that even when at temperatures below $200{ }^{\circ} \mathrm{C}$ the reaction is sluggish, hydroxyl groups are capable of reacting with epoxides as indicated in Fig. 2(a). On the other hand, the well known transesterification reaction between the ester and hydroxyl groups of the fatty acid precursor can also result in species of higher molecular weight and at least tetra-functionalized, as schematized in Fig. 2(b). Additionally, chain transfer reactions could also occur during free radical curing, transferring the activity of a growing polymer molecule to a monomer, polymer or solvent molecule [37-39]. As was reported by Lazar et al. [39], who investigated the influence of free radical initiation on the polymerization of dodecylmethacrylate, the long alkyl groups can also be a site of the attack of radicals by hydrogen atom abstraction. Transfer reaction can then cause a rise in the functionality of the monomer and can be extended to the branching and even cross-linking of the poly(dode-

(a) MOA (or MLA) GMA

Monomer with higher functionality<smiles>[R]C(=O)OCC(O)COC(=O)C(C)=C[Te]C1OC1COC(=O)C(C)=CCC</smiles>

\section{2}<smiles></smiles>

Fig. 2. Schematic reactions between an alcohol group and an epoxy group (a) and transesterification reaction (b). 
cylmethacrylate) macromolecules [39]. Thus, we believe that the synthesized precursors (MLA and MOA) should be a complex mixture of monomers with functionality 2 and a small amount of monomers with higher functionality and molecular weight and therefore, their free radical polymerization with styrene resulted also in cross-linked materials.

SEM micrographs (Figs. 3a and 3b) show a clear difference between the fractured surfaces of MLA/MOA - ST based materials and MLA/MOA - DVB materials. The former group presents homogeneous roughness all over the surface with signs of some plastic deformation related with their nodular type morphology while the latter group shows a comparatively much smooth surface, with very small cracks and ridges, according to almost completely fragile fracture.

During the propagation of the fracture in the materials prepared with ST, coarse slip bands are formed producing a characteristic river-like pattern. This plastic zone consumes the main part of the work of fracture. On the other hand, higher amount of bio-based precursors in the copolymers seems to increase slightly the roughness of the surfaces with striations appearing closer to each other.

The structure developed in these materials is comparable to that obtained from the reaction of unsaturated polyester resins and styrene by free-radical chain-growth copolymerization. In those cases, the polyester molecules are the cross-linkers while styrene act as the agent that links the nearby polyester molecules [40]. In these systems, the formation of micro or nanogels has been widely reported [40-43], being the size and structure of the formed gels strongly dependent on the concentration of styrene monomer and/or

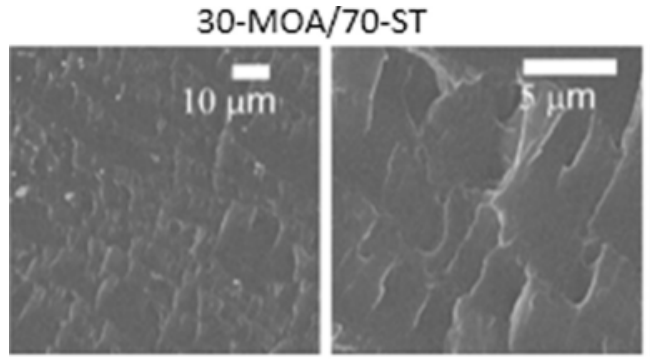

30-MLA/70-ST

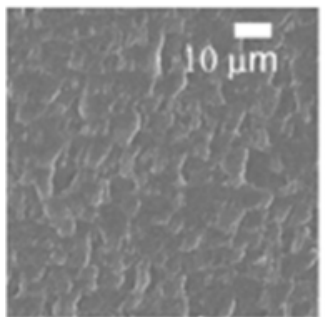

$1000 x$

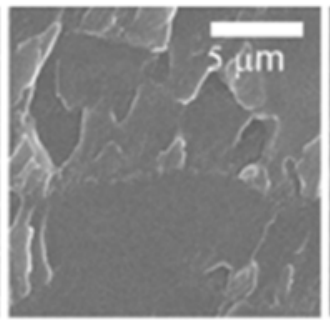

$5000 x$

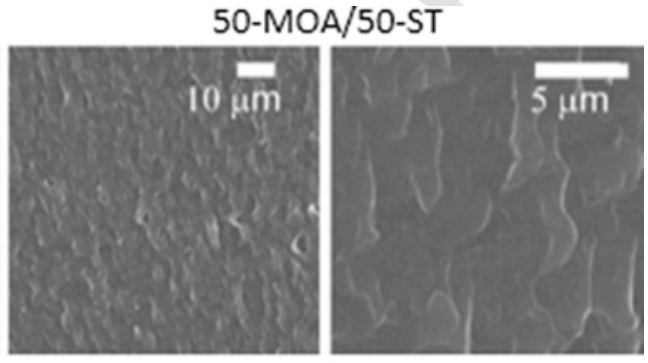

50-MLA/50-ST

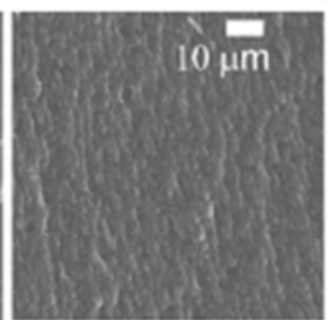

$1000 x$

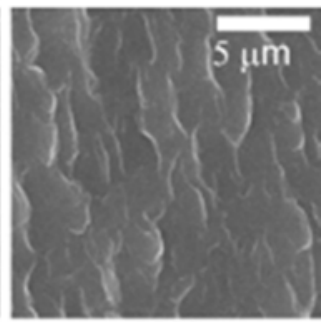

$5000 x$

Fig. 3a. SEM micrographs of MLA/MOA - ST materials.

50-MOA/50-DVB

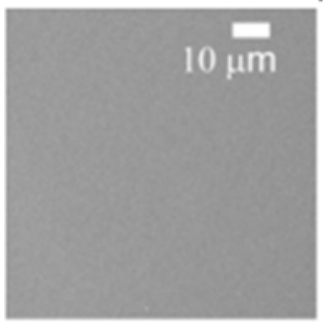

50-MLA/50-DVB

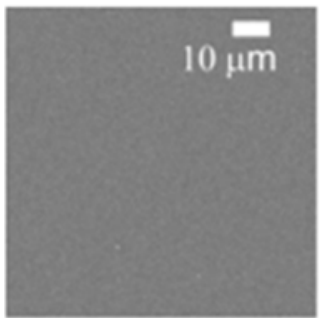

$1000 x$

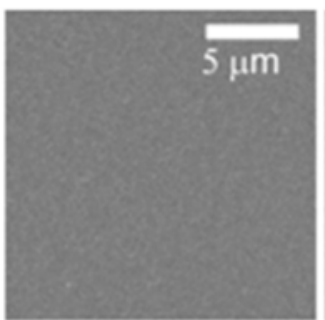

$5000 x$
70-MOA/30-DVB

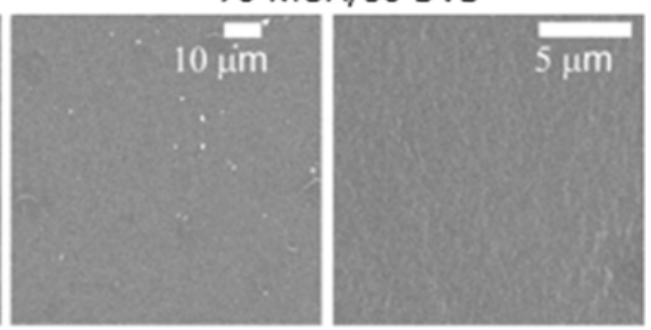

70-MLA/30-DVB

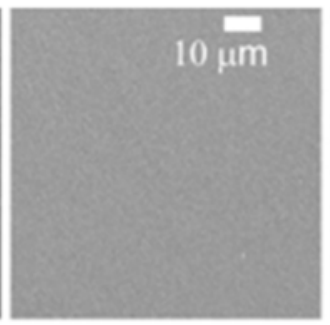

$1000 x$

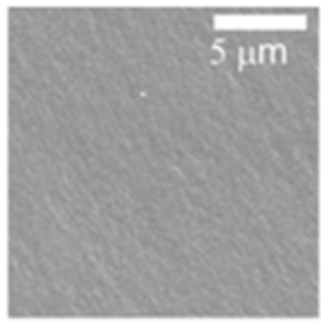

$5000 x$

Fig. 3b. SEM micrographs of MLA/MOA - DVB materials. 
the chemical structure of the polyester resin and as a consequence, the morphology of the final materials depend also on these factors. Yang and Lee (1988) and Mosiewicki et al. (2006) [40,41], for example, reported that at high styrene concentrations, i.e. low concentration of microgels connected by longer ST-ST chains, the individual micro/nano gel particles can be easily observed due to the styrene swelling effect. At low styrene concentration, i.e. high micro/nanogel content, the micro/nanogels are closely packed together; they tend to entangle and overlap with each other, so that no individual particles can be observed. Thus, the fracture pattern of the obtained samples could be associated to surfaces of materials with relatively low ST content since they present increased coalescence of the highly cross-linked nodules and consequently closer striations in the images. Moreover, nodular morphology, as the result of the growth of the network through the formation of microgels, their agglomeration into clusters and the linking of those clusters, was also observed in systems cross-linked with divinybenzene [42,44,45]. In fact, Rey et al. [44], who compared two systems based on the same dimethacrylate monomer polymerized with styrene or divinylbenzene comonomers indicated that the network based on DVB was the most highly cross-linked, exhibiting the most heterogeneous structure and the worst impact performance, observations that match the behavior of our samples. Besides, as in the case of ST, the size of the nodules seems to decreases as the DVB content in the samples decrease, leading to fractured surfaces with reduced unevenness.

The dynamic mechanical response of the obtained polymers is shown in Fig. 4a (shear storage modulus, $G^{\prime}$ ) and $4 \mathrm{~b}(\tan \delta$ ) as a function of temperature. Polymers containing MLA/MOA-ST present a clearly visible glass-rubber transition zone, while this transition is not observed for those polymers prepared from DVB, at least within the experimental window analyzed. Instead, a monotonous decrease in the shear storage modulus is observed, which is the typical behavior for highly cross-linked networks that degrade at temperatures lower than their Tgs.

Considering the MOA-ST and MLA-ST polymers, the curves show the classic trend with quasi plateaus at low and high temperatures connected by the region of modulus relaxation. The glassy modulus increases as styrene content increases (see Fig. 4a) for both bio-based precursors. However, it is interesting to note that the opposite tendency is observed when the rubbery modulus is analyzed. The higher the fatty acid based monomer content, the higher the rubbery $G^{\prime}$ (Fig. 4a).

At low temperatures, the shorter length of MLA monomer (in comparison with that of the MOA, whose aliphatic $\mathrm{C}=\mathrm{C}$ cannot participate in free radical polymerizations either) and the higher content of styrene contribute both to reduce polymer mobility and in consequence, to increase the glassy modulus of the resulting materials. In other words, as shorter is the dangling fatty acid chain the less is its plasticizing effect. In addition, the aromatic styrene ring contributes to the rigidity of the copolymer structure at temperatures below $\mathrm{Tg}$, even when it does not lead to an increase in crosslink density. However, at high temperatures the polymer mobility is higher and the trend in rubbery modulus is determined mostly by the cross-linking density and the rigidity between cross-linked points [46], which is higher for materials with higher content of MLA or MOA. Additionally, the "micro/nano gels" formed during the first stages of curing are domains of high cross-linking density [44,45] and thus comparatively more rigid and denser than the rest of the material and therefore, can act as reinforcement, increasing, consequently, the modulus at high temperature.

Fig. $4 \mathrm{~b}$ shows the curves of the tan $\delta$ for the obtained materials. Tgs (determined as the maximum in the damping factor curve) increase with increasing content of ST in both systems (prepared with MOA or MLA). These types of polymers present a complex mix of counteracting factors that can contribute to their dynamic-mechanical behavior: the plasticizing effect of the fatty acid chains free of movement (that is more important as longer is the chain) and the cross-linking structure (that increases as the bio-based precursor amount increased). On the other hand, very high styrene content ( $70 \mathrm{wt} \%$ in this case) in the copolymer leads to properties closer to those of the ST homopolymer, since longer ST-ST sequences are formed and thus, the $\mathrm{Tg}$ moves to higher temperatures. This effect was also observed by Mosiewicki et al. [46] for a system based in linseed oil maleated resins and ST at concentrations of ST higher than $60 \%$. Moreover, it is clearly noticed that the height of the tan $\delta$ peak also increases as the ST content in the formulation increases, corroborating that the cross-linkages occur through rather long and flexible ST-ST sequences, leading to materials with

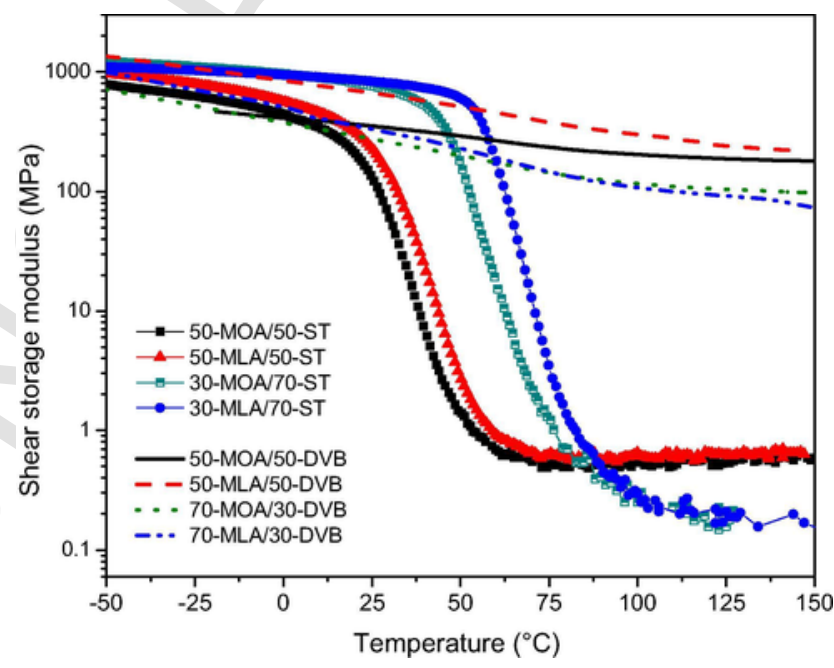

Fig. 4a. Shear storage modulus versus temperature curves of the obtained polymers. 


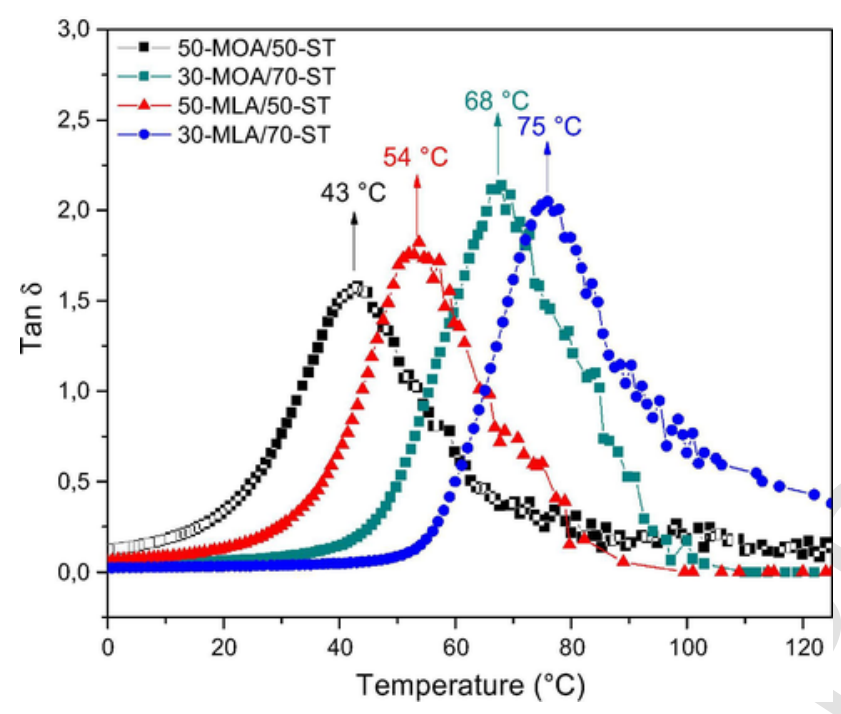

Fig. 4b. Tan $\delta$ versus temperature curves of the obtained polymers.

higher damping capability. A larger tan $\delta$ implies that the polymer is more likely viscous than elastic. Therefore, the decreasing cross-linking density enhanced the viscous properties of the polymers and then the damping properties, as was also observed in related works [35]. Regarding the effect of the bio-based precursor on the Tg values, the plasticizing effect of MOA, which is a longer and more mobile fatty acid chain than MLA, leads to copolymers of lower Tgs [25], confirming the very low reactivity of the C $=\mathrm{C}$ of the aliphatic chain of OA in free radical polymerization.

The cross-linking densities of the samples obtained using styrene, calculated from Eq. (3) and presented in Table 3, corroborate the previous statements: a higher styrene content in the formulations leads to copolymers containing more linear chains than their $50 \%$ ST counterparts, which in turn results in higher Tgs and lower rubbery modulus.

Tensile properties were only measured for the copolymers prepared with ST because the fragility of the samples cross-linked with DVB did not allow cutting them in the required dimensions to be tested. The trend in the Young's modulus corresponding to the ST-polymers series, presented in Table 3, is the same found in the dynamic mechanical response at room temperature (glassy state), as expected: as higher the styrene content, the higher is the rigidity of the material and so its Young's modulus. Regarding the effect of the precursor chain flexibility, it is not reflected in the modulus' values since they are calculated from the linear part of the tensile curve, at low applied loads. In addition, samples containing $70 \mathrm{wt} \%$ styrene do present a clear yield point and their elongation at break is considerably reduced in comparison with those of the polymers prepared with $50 \%$. Moreover, none of the materials presented strain hardening and hence it can be inferred that large scale orientation of chain molecules does not take place during the tests.

As was reported in a previous publication, the polymers obtained by cross-linking MLA and MOA precursors with styrene presented shape memory behavior [25]. On the contrary, the counterparts obtained by polymerizing the fatty acid monomers with DVB did not show these functional properties, which was attributed to their excessive cross-linking density that restrict significantly the mobility of these materials even at high temperatures. Accordingly, thermal tensile cycling tests were used to quantify the shape memory properties of MLA/ST and MOA/ST series. These cycles consisted in deforming the sample at relatively high temperature (around or above Tg) to set up a transitory shape, followed by cooling to fix the transitory shape and further recovery of the original length at high temperature. The chosen deformation was arbitrarily fixed at $50 \%$ in all cases and the high temperatures were selected from the results of the dynamic mechanical tests, being those: 60 and $75^{\circ} \mathrm{C}$ for $30 \%$ of MOA and MLA materials, $60^{\circ} \mathrm{C}$ for 50 -MLA/50-STand $45^{\circ} \mathrm{C}$ for 50 -MOA/50-ST. In all cases the low (fixing) temperature was well below $0{ }^{\circ} \mathrm{C}$. The summary of the shape memory properties, fixity $\left(R_{f}\right)$ and recovery $\left(R_{r}\right)$, obtained from the thermal cycles for all the samples is shown in Table 4.

Fig. 5 shows, as a few examples, tensile cycles for (a) 30-MOA/70-STat $75^{\circ} \mathrm{C}$ as triggering temperature, (b) 30-MLA/70-ST also at $75^{\circ} \mathrm{C}$, (c) 50-MOA/50-ST tested at $45^{\circ} \mathrm{C}$ and (d) 50-MLA/50-ST tested at $60^{\circ} \mathrm{C}$.

Table 3

Thermal and mechanical properties of obtained polymers.

\begin{tabular}{lllll}
\hline Sample & Cross-linking density $\left(\mathrm{mol} / \mathrm{m}^{3}\right)$ & Young's modulus $(\mathrm{MPa})$ & Yield strength (MPa) & Elongation at break (\%) \\
\hline 50-MOA/50-ST & $55.7 \pm 0.5$ & $243 \pm 55$ & $7.7 \pm 2.5$ & $20.1 \pm 7.9$ \\
50-MLA/50-ST & $48.0 \pm 10.2$ & $639 \pm 113$ & $21.1 \pm 3.0$ & $31.0 \pm 7.5$ \\
30-MOA/70-ST & $22.9 \pm 0.9$ & $891 \pm 101$ & $*$ & $5.6 \pm 4.2$ \\
30-MLA/70-ST & $22.5 \pm 0.1$ & $849 \pm 185$ & $*$ & $4.7 \pm 0.1$ \\
\hline
\end{tabular}

*Not observed. 
Table 4

Shape memory properties of styrene-fatty acid based polymers.

\begin{tabular}{|c|c|c|c|c|c|c|}
\hline \multirow[b]{2}{*}{ Sample } & \multirow{2}{*}{$\begin{array}{l}\text { Cycle number } \\
N\end{array}$} & \multicolumn{2}{|c|}{ Actuation force/stress } & \multirow{2}{*}{$\begin{array}{l}\text { Fixity (\%) } \\
R_{f}\end{array}$} & \multicolumn{2}{|c|}{ Recovery (\%) } \\
\hline & & Force $(\mathrm{N})$ & Stress $(\mathrm{kPa})$ & & $R_{r}$ & $R_{r}(\mathrm{~N})$ \\
\hline \multirow{3}{*}{$\begin{array}{l}\text { 50-MOA/50-ST } \\
\quad 45^{\circ} \mathrm{C}\end{array}$} & 1 & 4.9 & 473.0 & 98.8 & 99.2 & 92.9 \\
\hline & 2 & 4.5 & 434.4 & 100.0 & 88.2 & 94.9 \\
\hline & 3 & 4.2 & 405.4 & 99.1 & 82.9 & 94.0 \\
\hline \multirow{3}{*}{$\begin{array}{l}\text { 50-MLA/50-ST } \\
\quad 60^{\circ} \mathrm{C}\end{array}$} & 1 & 3.7 & 440.5 & 99.5 & 99.3 & 99.3 \\
\hline & 2 & 3.6 & 428.6 & 99.3 & 91.2 & 91.8 \\
\hline & 3 & 3.4 & 404.8 & 99.2 & 87.8 & 96.3 \\
\hline \multirow{3}{*}{$\begin{array}{l}\text { 30-MOA/70-ST } \\
\quad 60^{\circ} \mathrm{C}\end{array}$} & 1 & 3.3 & 412.5 & 99.2 & 84.6 & 84.6 \\
\hline & 2 & 2.7 & 337.5 & 99.3 & 80.0 & 94.6 \\
\hline & 3 & 2.7 & 337.5 & 98.9 & 75.0 & 93.8 \\
\hline \multirow{3}{*}{$\begin{array}{l}\text { 30-MOA/70-ST } \\
75^{\circ} \mathrm{C}\end{array}$} & 1 & 1.3 & 157.2 & 98.6 & 60.6 & 60.6 \\
\hline & 2 & 0.7 & 84.6 & 92.1 & 51.5 & 85.0 \\
\hline & 3 & 0.6 & 72.6 & 87.6 & 46.2 & 86.5 \\
\hline \multirow{3}{*}{$\begin{array}{l}\text { 30-MLA/70-ST } \\
60^{\circ} \mathrm{C}\end{array}$} & 1 & 7.4 & 831.5 & 99.2 & 45.9 & 45.9 \\
\hline & 2 & 3.4 & 382.0 & 98.5 & 26.2 & 57.1 \\
\hline & 3 & 1.9 & 213.5 & 97.7 & 14.2 & 54.2 \\
\hline \multirow{3}{*}{$\begin{array}{l}\text { 30-MLA/370-ST } \\
75^{\circ} \mathrm{C}\end{array}$} & 1 & 1.9 & 211.6 & 99.5 & 67.3 & 67.3 \\
\hline & 2 & 1.2 & 133.6 & 99.3 & 56.5 & 84.0 \\
\hline & 3 & 1.1 & 122.5 & 99.1 & 47.7 & 84.4 \\
\hline
\end{tabular}

In the results shown in Table 4 and Fig. $5 \mathrm{a}$ and b, it can be noticed that the first cycle is clearly distinct from the others: the recovery values are in the order of 60 and $67 \%$, respectively, and then continue to decrease as the number of cycles increases, but with minor differences respect to the previous cycle. Furthermore, the $R_{r}$ of the second and third cycles reach values of $52-56 \%$ and $46-48 \%$, respectively, indicating that the process is pretty irreversible after "training". In fact, the reversibility of the further cycles can be corroborated by the values of $\mathrm{R}_{\mathrm{r}}(\mathrm{N})$, that reach values higher than $80 \%$ in both cases. It is clear that this behavior can be correlated with their lower degree of reticulation due to the higher amount of ST used in the formulation of these materials. The cross-linking points connect longer sequences of ST-ST chains that can reorient during the first cycle. Above $\mathrm{Tg}$, the system with lower cross-linking density present the highest mobility and some weak interactions between chains are overcame during stretching in an irreversible way. This behavior is frequently described in literature, especially for thermoplastic shape memory polymers in which the chains are largely free to move about $\mathrm{Tg}[8,47,48]$. Moreover, when the samples prepared from MLA (i.e. 30-MLA/70-ST) are heated at lower temperature (i.e. $60^{\circ} \mathrm{C}$ ), their shape recovery is even poorer, as expected. Surprisingly, samples made from MOA (i.e. $30-\mathrm{MOA} / 70-\mathrm{ST}$ ) present the opposite behavior, reaching higher recovery values at $60^{\circ} \mathrm{C}$. This performance could be related again with the plasticizing effect of MOA (in comparison to MLA) that allow higher chain mobility at lower temperature, which results not as low as to compromise the stress the sample can bear. On the other hand, the copolymers with $50 \%$ ST exhibit a very high recovery that do not change appreciably with cycling, which is an indicative of a more complete reversible processes. The relative motion of segments and net-points determined by the cross-linking density is the primary mechanism of the SME in polymers [49]. Moreover, in thermoset polymers the shape recovery is given through covalently bonded net points [24], therefore it is expected that polymers with higher MOA or MLA content that present higher cross-linked density (and smaller distance between net points), show the best performance as shape memory materials. Overall, it can be noticed that both, the recovery and fixity values are really high, even when the switching temperature chosen for launching the temporary shape is not too different than the $\mathrm{Tg}$ of the polymers. In addition, the fixity values $\left(R_{f}\right)$ were in all cases higher that $87 \%$. On the other hand, it was found that at temperatures of about $\mathrm{Tg}+15^{\circ} \mathrm{C}$ most of the samples broke at very low strains. As it is known, the Young's modulus and the stress that an amorphous polymer can bear decrease with an increasing temperature [50]. Therefore, the temperature range of application of these polymers as shape memory materials is limited, although interesting.

Another important property related with the shape memory behavior is the recovery force generated by the materials when they are being used as an actuator, i.e. the actuation force $A_{f}$. In fact, one of the major limitations of the shape memory polymers in comparison with other shape memory materials (i.e. shape memory alloys and shape memory ceramics) is that the former, in general, exhibit lower strength and stiffness that restricts their use for many advanced applications (i.e. it only results in a small recovery force in the temperature change process) $[3,31,51]$. In order to overcome this drawback, some researchers added high stiffness nano/micro fillers to the polymeric matrix. For example Gall et al. [31] indicated that while their base shape memory resin (thermoset epoxy system) could only generate $300 \mathrm{mN}$ of actuation force, the corresponding composite with $20 \mathrm{wt} \% \mathrm{SiC}$ (average diameter of $300 \mathrm{~nm}$ ) generated $450 \mathrm{mN}$ for identical constraint conditions and specimen geometry. In a similar work, Rezanejad and Kokabi [51] indicated that the modulus of elasticity, the recovery temperature, the recovery force and force recovery rate of their cross- 

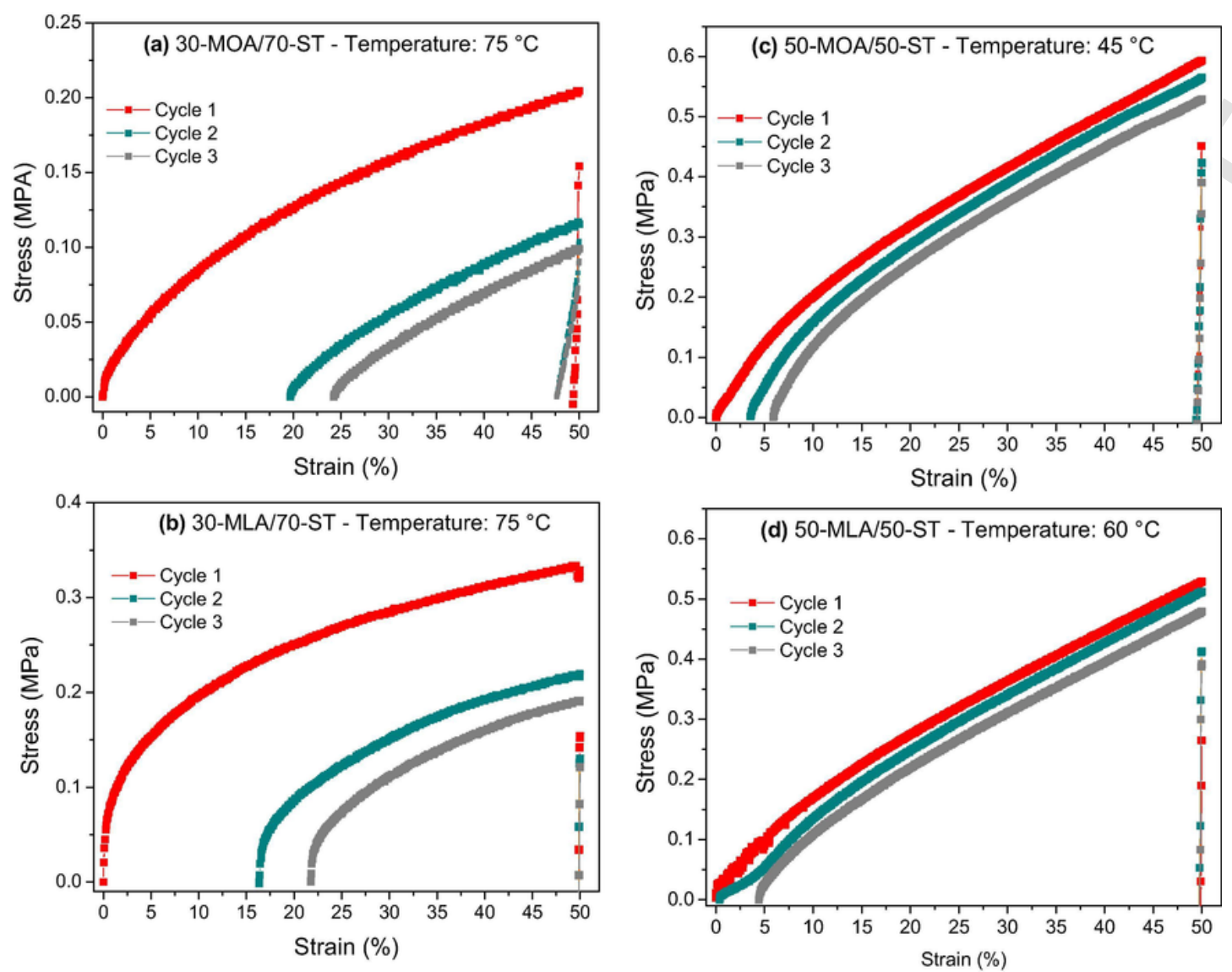

Fig. 5. Thermal tensile cycles of (a) MOA30-ST70 and (b) MLA30-ST70, both at $75^{\circ} \mathrm{C}$ switching temperature; (c) MOA50- ST50 at $45^{\circ} \mathrm{C}$ and (d) MLA50-ST50 at $60^{\circ} \mathrm{C}$ as switching temperature.

linked polyethylene/organoclay nanocomposites increased with increasing filler content, but final recovery strain decreases slightly. Specifically they showed that for the composite exhibiting the best performance ( $8 \mathrm{wt} \%$ clay) the final recovery strain decreases about $12 \%$ respect to that of the neat polymer while recovery stress (force generation) increases about $200 \%$. In our case it is clear that the actuation force/stress of the different materials depends also on their composition (stiffness) and testing temperature, as expected, being higher as lower is the temperature and higher is the elasticity of the bio-polymer (Table 4). But most important is that the actuation force/stress reached, in some cases, higher values than those reported previously for nano-reinforced shape memory polymers, even when it decreased with the number of cycles.

\section{Conclusions}

Bio-based polymeric precursors derived from oleic and lauric acids were synthesized and polymerized with styrene or divinylbenzene, leading to highly translucent and insoluble materials with differentiated mechanical response: those polymers based on DVB resulted very fragile and thus they could not be cut in specimens to be tested in tensile tests. Moreover, they did not exhibit appreciable rubber-glass transition or shape memory response in the range of temperature analyzed. On the other hand, the materials based on styrene presented the characteristics that allow good shape memory properties: a sharp transition (the storage modulus changes at least three orders of magnitude from the glassy to the rubber states) that can be used to quickly fix the secondary shape and activate shape recovery, and relative high deformability above the transition temperature that leads to shape recovery. Furthermore, it was observed that shape-memory properties varied with crosslink density, allowing obtaining bio-based materials with tailored shape-memory properties by simple varying the amount of cross-linker used in the polymerization.

\section{Acknowledgments}

The authors acknowledge the financial support provided by the Science and Technology National Promotion Agency (ANPCyT, Grant PICT-2016-2034) and the National University of Mar del Plata (Project 15/G494/ING500/17). We also thank CONICET for the fellowship awarded to Dr. Guillermina Capiel. 


\section{Data availability}

The raw/processed data required to reproduce these findings cannot be shared at this time as the data also forms part of an ongoing study.

\section{References}

[1] F. Pilate, A. Toncheva, P. Dubois, J. Raquez, Shape-memory polymers for multiple applications in the materials world, Eur. Polym. J. 80 (2016) $268-294$.

[2] Y. Liu, H. Du, L. Liu, J. Leng, Shape memory polymers and their composites in aerospace applications: a review, Smart Mater. Struct. 23 (2014)023001https:// doi.org/10.1088/0964-1726/23/2/023001.

[3] D. Ratna, J. Karger-Kocsis, Recent advances in shape memory polymers and composites: a review, J. Mater. Sci. 43 (2008) 254-269, https://doi.org/10.1007/ s10853-007-2176-7.

[4] L. Xue, S. Dai, Z. Li, Biodegradable shape-memory block co-polymers for fast self-expandable stents, Biomaterials 31 (2010) 8132-8140, https://doi.org/10. 1016/j.biomaterials.2010.07.043.

[5] A. Lendlein (Ed.), Shape-memory Polymers. Advances in Polymer Science, vol. 226, Springer-Verlag, Berlin, Heidelberg, 2010.

[6] M.E. Lamm, Z. Wang, J. Zhou, L. Yuan, X. Zhang, C. Tang, Sustainable epoxy resins derived from plant oils with thermo- and chemo-responsive shape memory behavior, Polym. (United Kingdom) 144 (2018) 121-127, https://doi.org/10.1016/j.polymer.2018.04.047.

[7] Y.-S. Joo, J.-R. Cha, M.-S. Gong, Biodegradable shape-memory polymers using polycaprolactone and isosorbide based polyurethane blends, Mater. Sci. Eng. C 91 (2018) 426-435, https://doi.org/10.1016/j.msec.2018.05.063.

[8] C. Meiorin, M.I. Aranguren, M.A. Mosiewicki, Vegetable oil/styrene thermoset copolymers with shape memory behavior and damping capacity, Polym. Int. 61 (2012) 735-742, https://doi.org/10.1002/pi.3231.

[9] S. Miao, P. Wang, Z. Su, S. Zhang, Vegetable -oil- based polymers as future polymeric biomaterials, Acta Biomater. 10 (2014) 1692-1704, https://doi.org/10. 1016/j.actbio.2013.08.040.

[10] Y. Xia, R.L. Quirino, R.C. Larock, Bio-based thermosetting polymers from vegetable oils, J. Renew. Mater. 1 (2013) 3-27, https://doi.org/10.7569/JRM.2012. 634103.

[11] A. Gandini, T.M. Lacerda, Polymers from Plant Oils, second ed., John Wiley \& Sons, Inc. and Scrivener Publishing LLC, 2019.

[12] Y. Lu, R.C. Larock, Novel polymeric materials from vegetable oils and vinyl monomers: preparation, properties, and applications, ChemSusChem. 2 (2009) 136-147, https://doi.org/10.1002/cssc.200800241.

[13] A. Campanella, J.J. La Scala, R.P. Wool, The use of acrylated fatty acid methyl esters as styrene replacements in triglyceride-based thermosetting polymers, Polym. Eng. 49 (2009) 2384-2392, https://doi.org/10.1002/pen.21486.

[14] M.A. Mosiewicki, M.I. Aranguren, Recent developments in plant oil based functional materials, Polym. Int. 65 (2015) 28-38, https://doi.org/10.1002/pi.5033.

[15] C. Zhang, T.F. Garrison, S.A. Madbouly, M.R. Kessler, Recent advances in vegetable oil-based polymers and their composites, Prog. Polym. Sci. 71 (2017) 91-143, https://doi.org/10.1016/j.progpolymsci.2016.12.009.

[16] L. Montero De Espinosa, M.A.R. Meier, Plant oils: the perfect renewable resource for polymer science, Eur. Polym. J. 47 (2011) 837-852, https://doi.org/10. 1016/j.eurpolymj.2010.11.020.

[17] J.J. La Scala, J.M. Sands, J.A. Orlicki, E.J. Robinette, G.R. Palmese, Fatty acid-based monomers as styrene replacements for liquid molding resins, Polymer (Guildf). 45 (2004) 7729-7737, https://doi.org/10.1016/j.polymer.2004.08.056.

[18] F. Li, R.C. Larock, New soybean oil-styrene-divinylbenzene thermosetting copolymers. V. Shape memory effect, J. Appl. Polym. Sci. 84 (2002) 1533-1543, https: //doi.org/10.1002/app.10493.

[19] C. Meiorin, M.I. Aranguren, M.A. Mosiewicki, Polymeric networks based on tung oil: reaction and modification with green oil monomers, Eur. Polym. J. 67 (2015) 551-560, https://doi.org/10.1016/j.eurpolymj.2015.01.005.

[20] Z. Wang, L. Yuan, M.S. Ganewatta, M.E. Lamm, M.A. Rahman, J. Wang, S. Liu, C. Tang, Plant Oil-derived epoxy polymers toward sustainable biobased thermosets, Macromol. Rapid Commun. 38 (2017) 1-6, https://doi.org/10.1002/marc.201700009.

[21] T. Tsujimoto, K. Takeshita, H. Uyama, Bio-based epoxy resins from epoxidized plant oils and their shape memory behaviors, JAOCS, J. Am. Oil Chem. Soc. 93 (2016) 1663-1669, https://doi.org/10.1007/s11746-016-2907-5.

[22] B. Guo, Y. Chen, Y. Lei, L. Zhang, W.Y. Zhou, A.B.M. Rabie, J. Zhao, Biobased poly(propylene sebacate) as shape memory polymer with tunable switching temperature for potential biomedical applications, Biomacromolecules 12 (2011) 1312-1321, https://doi.org/10.1021/bm2000378.

[23] O. Goerz, H. Ritter, Polymers with shape memory effect from renewable resources: crosslinking of polyesters based on isosorbide, itaconic acid and succinic acid, Polym. Int. 62 (2013) 709-712, https://doi.org/10.1002/pi.4443.

[24] T. Calvo-Correas, N. Gabilondo, A. Alonso-Varona, T. Palomares, M.A. Corcuera, A. Eceiza, Shape-memory properties of crosslinked biobased polyurethanes, Eur. Polym. J. 78 (2016) 253-263, https://doi.org/10.1016/j.eurpolymj.2016.03.030.

[25] G. Capiel, N.E. Marcovich, M.A. Mosiewicki, From the synthesis and characterization of methacrylated fatty acid based precursors to shape memory polymers, Polym. Int. 68 (2018) 546-554, https://doi.org/10.1002/pi.5744.

[26] L.A. Kunte, A. Gennadios, S.L. Cuppett, M.A. Hanna, C.L. Weller, Cast films from soy protein isolates and fractions, Cereal Chem. 74 (1997) 115-118, https:// doi.org/10.1094/CCHEM.1997.74.2.115.

[27] F.M. Monedero, M.J. Fabra, P. Talens, A. Chiralt, Effect of oleic acid-beeswax mixtures on mechanical, optical and water barrier properties of soy protein isolate based films, J. Food Eng. 91 (2009) 509-515, https://doi.org/10.1016/j.jfoodeng.2008.09.034.

[28] F.T. García, P.J.D.A. Sobral, Effect of the thermal treatment of the filmogenic solution on the mechanical properties, color and opacity of films based on muscle proteins of two varieties of Tilapia, LWT Food Sci. Technol. 38 (2005) 289-296, https://doi.org/10.1016/j.lwt.2004.06.002.

[29] P.J. Flory, Principles of Polymer Chemistry, Cornell University Press, 1953.

[30] R.F. Landel, L.E. Nielsen, Mechanical Properties of Polymers and Composites, CRC Press, 1993.

[31] K. Gall, M.L. Dunn, Y. Liu, D. Finch, M. Lake, N.A. Munshi, Shape memory polymer nanocomposites, Acta Mater. 50 (2002) 5115-5126, https://doi.org/10. 1016/S1359-6454(02)00368-3.

[32] A. Casariego, B.W.S. Souza, M.A. Cerqueira, J.A. Teixeira, L. Cruz, R. Diaz, A.A. Vicente, Chitosan/clay films ' properties as affected by biopolymer and clay micro/nanoparticles ' concentrations, Food Hydrocoll. 23 (2009) 1895-1902, https://doi.org/10.1016/j.foodhyd.2009.02.007.

[33] B. Cuq, N. Gontard, J. Cuq, S. Guilber, Functional properties of myofibrillar protein based biopackaging as affected by film thickness, J. Food Sci. 61 (1996) 580-584, https://doi.org/10.1111/j.1365-2621.1996.tb13163.x.

[34] M. Pereda, A.G. Ponce, N.E. Marcovich, R.A. Ruseckaite, J.F. Martucci, Chitosan-gelatin composites and bi-layer films with potential antimicrobial activity, Food Hydrocoll. 25 (2011) 1372-1381, https://doi.org/10.1016/j.foodhyd.2011.01.001.

[35] G. Odian, Principles of Polymerization, John Wiley \& Sons, 2004.

[36] L. Shechter, J. Wynstra, Glycidyl ether reactions with alcohols, phenols, carboxylic acids, and anhydrides, Ind. Eng. Chem. 48 (1956) 86-93.

[37] P.J. Flory, The mechanism of vinyl polymerizations, J. Am. Chem. Soc. 59 (1937) 241-253, https://doi.org/10.1021/ja01281a007.

[38] J.L. O'Brien, F. Gornick, Chain transfer in the polymerization of methyl methacrylate. I. Transfer with monomer and thiols. The mechanism of the termination reaction at $60^{\circ} 1$, J. Am. Chem. Soc. 77 (1955) 4757-4763, https://doi.org/10.1021/ja01623a019.

[39] M. Lazár, L. Hrčková, A. Fiedlerová, E. Borsig, Crosslinking during radical polymerization of dodecyl methacrylate, Macromol. Mater. Eng. 283 (2000) 88-92, https://doi.org/10.1002/1439-2054(20001101)283:1<88::AID-MAME88 > 3.0.CO;2-N.

[40] Y.S. Yang, L.J. Lee, Microstructure formation in the cure of unsaturated polyester resins, Polymer (Guildf). 29 (1988) 1793-1800, https://doi.org/10.1016/ 0032-3861(88)90393-X. 
[42] S. Ziaee, G.R. Palmese, Effects of temperature on cure kinetics and mechanical properties of vinyl-ester resins, Am. Chem. Soc. Polym. Prepr. Div. Polym. Chem. 37 (1999) 725-744, https://doi.org/10.1002/(SICI)1099-0488(19990401)37:7 < 725::AID-POLB23 > 3.0.CO;2-E.

[43] Z. Guo, H. Sautereau, D.E. Kranbuehl, Structural evolution and heterogeneities studied by frequency-dependent dielectric sensing in a styrene/dimethacrylate network, Macromolecules 38 (2005) 7992-7999, https://doi.org/10.1021/ma050788b.

[44] L. Rey, J. Duchet, J. Galy, H. Sautereau, D. Vouagner, L. Carrion, Structural heterogeneities and mechanical properties of vinyl/dimethacrylate networks synthesized by thermal free radical polymerisation, Polymer (Guildf). 43 (2002) 4375-4384, https://doi.org/10.1016/S0032-3861(02)00266-5.

[45] K. Dušek, Are cured thermoset resins inhomogeneous?, Macromol. Chem. 240 (1996).

[46] M. Mosiewicki, M.I. Aranguren, J. Borrajo, Mechanical properties of linseed oil monoglyceride maleate/styrene copolymers, J. Appl. Polym. Sci. 97 (2005) 825-836, https://doi.org/10.1002/app.21790.

[47] M.L. Auad, V.S. Contos, S. Nutt, M.I. Aranguren, N.E. Marcovich, Characterization of nanocellulose- reinforced shape memory polyurethanes, Int. J. Pharm. Technol. 57 (2008) 651-659, https://doi.org/10.1002/pi.

[48] X. Luo, P.T. Mather, Preparation and characterization of shape memory elastomeric composites, Macromolecules 42 (2009) 7251-7253, https://doi.org/10. $1021 /$ ma9015888.

[49] X.L. Wu, S.F. Kang, X.J. Xu, F. Xiao, X.L. Ge, Effect of the crosslinking density and programming temperature on the shape fixity and shape recovery in epoxy-anhydride shape-memory polymers, J. Appl. Polym. Sci. 131 (2014) 1-10, https://doi.org/10.1002/app.40559.

[50] J. Richeton, S. Ahzi, K.S. Vecchio, F.C. Jiang, R.R. Adharapurapu, Influence of temperature and strain rate on the mechanical behavior of three amorphous polymers: characterization and modeling of the compressive yield stress, Int. J. Solids Struct. 43 (2006) 2318-2335, https://doi.org/10.1016/j.ijsolstr.2005.06.040.

[51] S. Rezanejad, M. Kokabi, Shape memory and mechanical properties of cross-linked polyethylene/clay nanocomposites, Eur. Polym. J. 43 (2007) 2856-2865, https://doi.org/10.1016/j.eurpolymj.2007.04.031. 